\section{HYPERVENTILATION IN CARBON-MONOXIDE POISONING}

BY

\section{G. L. LEATHART, M.D., M.R.C.P.}

Nuffield Department of Industrial Health, the Medical School, King's College, Newcastle upon Tyne

The recent revival of interest in the use of $5 \%$ or $7 \%$ carbogen in the treatment of carbon-monoxide poisoning has prompted the description of four unusual cases in which gross hyperventilation occurred. The investigation of these cases was not very thorough, but such cases are seen so seldom that it is felt that even this incomplete report may be of value in stimulating further research.

Hyperventilation in carbon-monoxide poisoning was noted by Haldane (1895) in experiments performed upon himself, but Drinker (1938) concluded that "increased breathing is not a prominent feature." He felt that those patients in whom it occurred would receive especial benefit from inhalation of carbon-dioxide mixtures because Haggard and Henderson (1921) had demonstrated a falling carbon-dioxide content of arterial blood in dogs poisoned with carbon monoxide. A low blood carbon-dioxide content may, however, be due to either respiratory alkalosis (as suggested by Drinker) or to non-respiratory acidosis, and the latter condition would be less likely to benefit from inhalation of carbon dioxide. The $p \mathrm{H}$ of the blood would distinguish between these two conditions, but this does not appear to have been measured either in animals or in man.

The object of this paper is to report four cases in which hyperventilation was a striking clinical feature, and was accompanied by non-respiratory acidosis. The demonstration of acidosis in these patients not only throws doubt on the advisability of $5 \%$ or $7 \%$ carbogen as a routine treatment but also contributes to our understanding of why the patients sometimes remain in coma after treatment has removed all but insignificant traces of carbon monoxide from the blood.

Methods.-Four patients showing hyperventilation during carbon-monoxide poisoning were studied. An anaerobic blood sample was taken from a brachial artery as soon as possible after admission and was kept in iced water until analysis, which usually took place within half an hour. Hydrogen-ion concentration was measured at $38^{\circ} \mathrm{C}$. with the simple electrode system recently described (Leathart, 1961). The carbon-dioxide content of plasma was estimated with the Haldane blood-gas apparatus and the $\mathrm{pCO}_{2}$ was calculated from the nomograms of Peters and Van Slyke (1932). The concentration of carboxyhaemoglobin was estimated on the same sample by the method of Lawther and Apthorp (1955). All patients were treated with inhalations of $100 \%$ oxygen by face-mask for the first four hours after admission.

\section{Results}

The results of the analysis of arterial blood are shown in the Table. There is no doubt that the carbon-dioxide content of plasma was much reduced in all cases and the $p H$ was also below normal. In Case 3 this might have been due to the long interval between collection and analysis of the sample, but if this were the explanation one would have expected a higher carbon-dioxide content. It is concluded that the blood was excessively acid in all cases.

\section{Case Reports}

Case 1.-A woman aged 61 was found with her head in a gas-oven. On admission to hospital she was deepiy unconscious, with a generalized increase of muscle tone, pulse rate 140 a minute, and blood-pressure $110 / 70 \mathrm{~mm}$. $\mathrm{Hg}$. There was marked hyperventilation suggesting the possibility of coincident aspirin poisoning. A stomach wash-out, however, revealed no tablets, and a sample of urine collected a few hours later contained no detectable salicylate. In 24 hours she had recovered fully and was transferred to a mental hospital.

Case 2.-An accountant aged 40 was working late in his office and was seen to be well at 9.15 p.m. At 8.45 a.m. the following morning he was found in the office with the gas turned on but unlit. He was deeply unconscious with strikingly deep and rapid respiration suggesting a condition of "air-hunger." Pulse rate was 120 a minute with numerous extrasystoles, and remained at that level for 24 hours. Blood-pressure was $120 / 80$. There were no localizing signs in the central nervous system. In view of the hyperventilation a catheter specimen of urine was examined for salicylate but none was detected. Four hours later his coma was unaltered and his hyperventilation continued. The stomach was washed out and a pint $(570 \mathrm{ml}$.) of normal saline, to which had been added four heaped teaspoonfuls of sodium bicarbonate, was left in it. But a blood sample taken on admission was later shown to contain neither barbiturate nor salicylate. At 6 p.m. he was still unconscious and breathing deeply. Serum electrolytes showed an anion deficit ( $\mathrm{Na} 156 ; \mathrm{K} 4.7 ; \mathrm{Cl} 108 ; \mathrm{CO}_{2} 21.5 \mathrm{mEq} / 1$.). Lumbar puncture revealed normal cerebrospinal fluid at normal pressure. At 9 a.m. the next day he was rousable but confused, and the hyperventilation continued. Two days after admission he was in a normal state but had no memory for the events of the preceding 48 hours. It should be noted that in this man the blood carboxyhaemoglobin was not high enough to account for the deep coma.

Case 3.-A woman aged 58 was found unconscious in her nightdress in the doorway between the kitchen and the sitting-room at 1 p.m. All taps of the gas cooker were turned on. Her daughter had left her in bed at 7 a.m. On admission to hospital she was deeply unconscious but hyperventilating. The pulse was regular at 88 a minute, and blood-pressure was $120 / 60$. There were no localizing signs in the central nervous system. The next day she was rousable but incoherent. Forty-eight hours after admission she had returned to normal. The carboxyhaemoglobin level was not high enough to account for the coma.

Case 4.-At between 8 and 9 a.m. a man aged 66 put his head in the oven and turned the gas on. He was found by neighbours at about 1.30 p.m. semi-conscious in a gasfilled room and was seen in the casualty department at 2.15 p.m. He was cyanosed but breathing well, and was given $5 \%$ carbogen. His pulse rate was 128 a minute, bloodpressure 190/120. At 2.40 p.m. he was conscious but confused, was hyperventilating markedly although he was no longer having carbogen, and there was a tremor of both arms (possibly because he was very cold) but no other abnormal signs. An arterial blood sample was taken at about 2.50 p.m., when he had been breathing air for at least 10 minutes. After one hour of breathing pure oxygen by B.L.B. mask his ventilation rate was shown to be $131 . / \mathrm{min}$., which is nearly twice normal for a patient lying in bed. The next morning he was in good health and was transferred to psychiatric care.

\begin{tabular}{c|c|c|c|c}
\multicolumn{5}{c}{ Analysis of Arterial Blood } \\
\hline Case No. & $\begin{array}{c}\text { COHb } \\
(\%)\end{array}$ & $p \mathrm{H}$ & $\begin{array}{c}\mathrm{CO}_{2} \text { Content } \\
\text { of Plasma } \\
(\mathrm{mM} / 1 .)\end{array}$ & $\begin{array}{c}\mathrm{pCO}_{2} \\
(\mathrm{~mm} . \mathrm{Hg})\end{array}$ \\
\hline 1 & 39 & $7 \cdot 34$ & $\begin{array}{c}14 \cdot 1 \\
8.9\end{array}$ & 24 \\
$3^{*}$ & 29 & $7 \cdot 18$ & 21 \\
4 & $16 *$ & $7 \cdot 12^{*}$ & $9.6 *$ & $27 *$ \\
& 38 & $7 \cdot 32$ & 14.2 & 26.5
\end{tabular}

- The blood sample was kept in iced water for 18 hours before analysis. 


\section{Discussion}

Hyperventilation is not common in cases of carbonmonoxide poisoning; it was not observed in 42 other patients who were admitted to this hospital over the same period. In the single case reported by Plum and Swanson (1959) hyperventilation began 24 hours after exposure to coal-gas and was accompanied by a rising arterial $p \mathrm{H}$. This appears to be a different condition from the one described here. Apthorp, Bates, Marshall, and Mendel (1958) inhaled carbon monoxide for 80 to 120 minutes during exercise but recorded no increase in minute volume. All showed an increase in pulse rate, and Apthorp also had an increasing respiratory frequency over the last few minutes of this inhalation. Stertorous breathing is, however, mentioned as a feature of carbon-monoxide poisoning in standard textbooks, and hyperventilation was noted by Haggard and Henderson (1921). They reported hyperventilation in two dogs that were subjected to comparatively low concentrations of carbon monoxide (which would, nevertheless, have been fatal in man) for long periods-that is, $0.17 \%$ or $0.16 \%$ for six hours and nine hours respectively. The experiments in which there was no hyperventilation were short-lived ones in which the animals died 30 to 50 minutes after starting to inhale $0.5 \%$ carbon monoxide.

It will be noted that three of the four cases reported here were exposed to carbon monoxide for long periods, and this confirms Drinker's (1938) statement that hyperventilation depends on lengthy exposure. Exposure amounted to about five hours in Case 4, but it is probable that the period was even longer in Cases 2 and 3. It must therefore be presumed that the carbon-monoxide concentration was not particularly high and that the haemoglobin came into equilibrium with inhaled carbon monoxide at a non-fatal level.

It is presumed that the long period of tissue anoxia in these patients led to excessive production of lactic acid, as originally described by Araki (1891), and that this was the cause of the low plasma $p H$. This suggestion is supported by the analysis of serum electrolytes in Case 2. Hyperventilation and the low carbon-dioxide content of plasma were secondary changes. This interpretation runs counter to that of Haggard and Henderson (1921), who believed that carbon monoxide was a respiratory stimulant and that the low plasma carbon-dioxide content was due to hyperventilation. They interpreted the excessive lactic-acid production as a reaction to alkalosis. However, the dissociation curves they plotted for one of their dogs strongly suggest that the blood became more acid, and they were probably mistaken in assuming that the dissociation constant was not altered by the appearance of carboxyhaemoglobin and of lactic acid in the blood.

One unusual feature of Cases 1, 2, and 3 was the long period of coma. This may be connected with the acidity of the blood, for Kety, Polis, Nadler, and Schmidt (1948) demonstrated a fall in cerebral uptake of oxygen in diabetic coma (in which the average arterial $p \mathrm{H}$ was 6.98), despite an increased blood flow, and postulated an effect of high acidity on the metabolism of the brain. Such an effect might also explain a point which puzzled Haldane (1895)-that exercise brought on cerebral symptoms which were absent at rest. He felt that exercise could not increase the metabolism of the brain enough to cause local anoxia, but it may be that anoxia in exercising muscles led to the production of acid metabolites and to a consequent fall in cerebral uptake of oxygen.

Although it is suggested here that both hyperventilation and coma may have been due to circulating acid metabolites this is unlikely to have been the only cause. In these cases the $p \mathrm{H}$ was not as low as that associated with either hyperventilation (less than 7.20) or coma (less than 7.14) in the diabetic patients of Kety et al. (1948). The thresholds may, however, be different in a brain previously rendered anoxic by carbon monoxide.

It seems likely that inhalations of $5 \%$ or $7 \%$ carbogen would be harmful to patients of the type described here, and it is suggested that only pure oxygen should be used when the patient is obviously hyperventilating.

Finally, it must be stressed that when coma is prolonged after carbon-monoxide poisoning the most likely cause is another poison-aspirin or barbituratetaken simultaneously. It is important to exclude this possibility before adopting simple expectant treatment.

\section{Summary}

Measurement of the $p H$ of arterial blood in four patients who were hyperventilating while suffering from coal-gas poisoning revealed a non-respiratory acidosis, which may have contributed to their prolonged coma.

It is suggested that patients of this type are better treated with pure oxygen than with $5 \%$ or $7 \%$ carbogen.

\section{REFERENCES}

Apthorp, G. H., Bates, D. V., Marshall, R., and Mendel, D. (1958). Brit. med. J., 2, 476

Araki, T. (1891). quoted by Haggard and Henderson (1921).

Drinker, C. K. (1938) Carbon Monoxide Asphyxia. Oxford Univ. Press, New York.

Haggard, H. W., and Henderson, Y. (1921). J. biol. Chem., 47, 421.

Haldane, J. (1895). J. Physiol. (Lond.), 18, 430.

Kety, S. S., Polis, B. D., Nadler, C. S., and Schmidt, C. F. (1948) J. clin. Invest., 27, 500

Lawther, P. J., and Apthorp, G. H. (1955). Brit. J. industr. Med., 12, 326 .

Leathart, G. L. (1961). Lancet, 1, 88

Peters, J. P., and Van Slyke, D. D. (1932). Quantitative Clinical Chemistry, vol. 2. Baillière, Tindall and Cox, London.

Plum, F, and Swanson, A. G. (1959). Arch. Neurol. Psychiat. (Chic.), 81, 535 .

A revised British Standard specification for hypodermic syringes for insulin injection (Luer fitting) (B.S. 1619:1962) has, with the approval of the British Diabetic Association, introduced the $2.0 \mathrm{ml}$. size syringe to supersede the $1.5 \mathrm{ml}$. size. Scale intervals of $0.05 \mathrm{ml}$. have been retained. Other modifications have been made to the specification. A glass or ceramic piston may be used as an alternative to metal pistons in metal-and-glass syringes. The test for leakage of the conical tip when fitted to a needle has been made more realistic in terms of present requirements, and relevant dimensions for insulin syringes are specified in order to provide basic data for the design of a carrying case. In specifying the Luer conical fitting (6\% taper) the standard conforms with others for hypodermic equipment. The B.S.I. Committee responsible for these standards agreed unanimously that the Luer conical fitting should be generally adopted in the United Kingdom because of the greater strength of the syringe needle and the more effective grip attained between the syringe nozzle and the mount. All syringes for insulin injection made to comply with this standard must bear the B.S.I.'s certification mark. This mark is issued only under licence, and full details should be obtained from the B.S.I. Copies of this standard may be obtained from the B.S.I. Sales Branch, 2 Park Street, London W.1. (Price 5s. each, postage extra to nonsubscribers.) 